\title{
Transradial balloon aortic valvuloplasty: a case report
}

\author{
(1) Nikola Crnčević*, \\ - Andrija Matetić, \\ DFrane Runjić, \\ Olvica Kristić
}

University Hospital Centre Split, Split, Croatia
KEYWORDS: balloon aortic valvuloplasty, aortic stenosis, transradial, frail. CITATION: Cardiol Croat. 2021;16(9-10):297. | https://doi.org/10.15836/ccar2021.297

*ADDRESS FOR CORRESPONDENCE: Nikola Crnčević, Klinički bolnički centar Split, Spinčićeva 1, HR-21000 Split, Croatia. / Phone: +38598741324 / E-mail: ncrncev1@gmail.com

ORCID: Nikola Crnčević, https://orcid.org/0000-0002-1399-3406 • Andrija Matetić, https://orcid.org/0000-0001-9272-6906 Frane Runjić, https://orcid.org/0000-0001-6639-5971 • Ivica Kristić, https://orcid.org/0000-0002-9882-9145

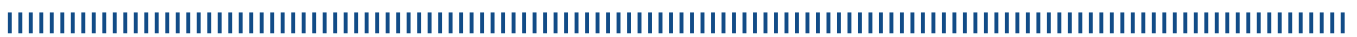

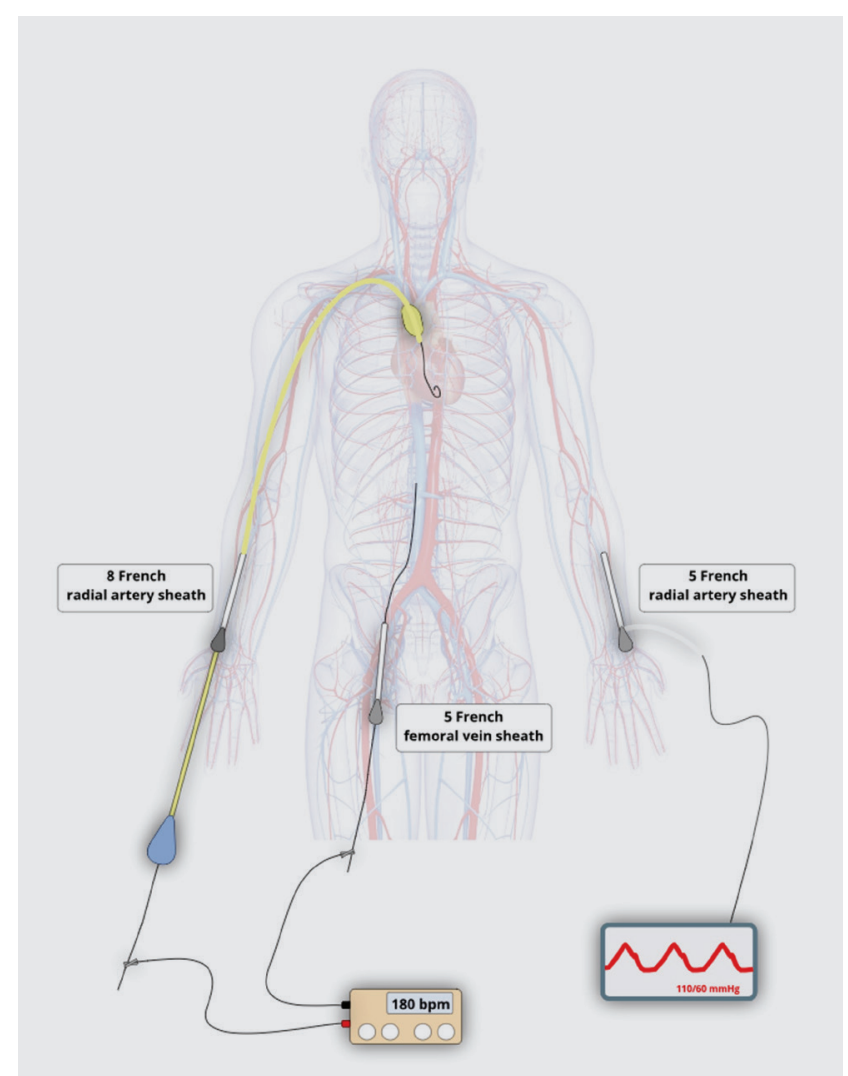

FIGURE 1. Vascular access planning and feasibility.
Background and Aims: Balloon aortic valvuloplasty (BAV) is usually used as a bridge to percutaneous or surgical aortic valve intervention. While BAV is traditionally performed via transfemoral approach, transradial BAV is a safe and feasible alternative ${ }^{1,2}$. We present a case of BAV performed via transradial access at the University Hospital Centre Split, which to our knowledge, is a first time this procedure was performed in Croatia.

Protocol presentation: 86-year-old lady was hospitalized on the vascular surgery department with symptoms of critical limb ischemia. Upon preoperative examination a strong heart murmur was noticed, with ECG changes suggestive of left ventricle strain. An echo was performed revealing an ejection fraction of $30 \%$, and a low flow - low gradient aortic stenosis (MPG $38 \mathrm{~mm} \mathrm{Hg}$, and Vmax $3.7 \mathrm{~m} / \mathrm{s}$ ). A CTA of the aorta revealed a chronic infrarenal dissection and an occlusion of the right iliac artery, basically disabling the classic femoral access. We decided to perform a balloon aortic valvuloplasty using radial access, as described in the SOFTLY-II trial ${ }^{3}$. Right radial access was obtained using a $6 \mathrm{~F}$ sheath and a contralateral radial artery was cannulated for pressure monitoring during the procedure and a $5 \mathrm{~F}$ sheath was placed in the femoral vein. After aortic valve crossing, a $260 \mathrm{~cm}$ wire (Medtronic CONFIDA) was placed in the left ventricle apex. At that point the $6 \mathrm{~F}$ sheath was exchanged with an 8F sheath (Figure 1). A non-compliant 18x40mm (Bard Atlas Gold) balloon was used during rapid pacing over the wire at 180/ min (positive electrode at the short wire placed in femoral vein and negative on the wire in the LV). Periprocedural analgosedation with propofol in the bolus-continuous infusion scheme was used during the rapid pacing.

Conclusions: Transradial BAV is a safe alternative to transfemoral BAV, especially in old and frail adults waiting for TAVR, while minimizing the bleeding risk, and femoral access complications.

\section{RECEIVED:}

July 30, 2021

ACCEPTED:

1. Tumscitz C, Di Cesare A, Balducelli M, Piva T, Santarelli A, Saia F, et al. Safety, efficacy and impact on frailty of mini-invasive radial balloon aortic valvuloplasty. Heart. 2021 Jun;107(11):874-880. https://doi.org/10.1136/heartjnl-2020-318548

2. Di Cesare A, Tonet E, Campo G, Tumscitz C. Snuffbox approach for balloon aortic valvuloplasty: A case series. Catheter Cardiovasc Interv. 2021 Apr 1;97(5):E743-E747. https://doi.org/10.1002/ccd.29196

3. Tumscitz C, Balducelli M, Saia F, Santarelli A, Piva T, Preti G, et al. TCT-478 Results of the Italian Register of the Safety and Feasibility of Transradial Mini-Invasive Balloon Aortic Valvuloplasty (Softly II). J Am Coll Cardiol. 2019 0ct; 74(13_Supplement):B473. https://doi.org/10.1016/j.jacc.2019.08.572 